\title{
L'interdisciplinarité à l'épreuve de la pratique : l'exemple d'un espace protégé
}

\section{Jean-Claude Génot}

Chargé de la protection de la nature, Syndicat de Coopération pour le Parc naturel régional des Vosges du Nord, Réserve de biosphère, BP 24 , 67290 La Petite-Pierre, France

Natures Sciences Sociétés 11, 413-418 (2003)

DOI : 10.1016/S1240-1307(03)00121-3

Dans le numéro 4/2003 de NSS, le titre du « Regard» consacré à J.-C. Génot comportait une erreur. Il faut lire «L'interdisciplinarité à l'épreuve de la pratique : l'exemple d'un espace protégé ». En effet, J.-C. Génot travaille non pas dans une réserve naturelle ou un parc national, mais dans un parc naturel régional.

Auteur correspondant : jc.genot@parc-vosges-nord.fr 